\title{
Analysis of the Load Sharing Behaviour and Cushion Failure Mode for a Disconnected Piled Raft
}

\author{
Xiao-jun Zhu ${ }^{1,2}$ \\ ${ }^{1}$ College of Civil Science and Engineering, Yangzhou University, Jiangsu 225127, China \\ ${ }^{2}$ School of Civil Engineering, Southeast University, Nanjing, Jiangsu 210096, China \\ Correspondence should be addressed to Xiao-jun Zhu; zhuxiaojun@yzu.edu.cn
}

Received 19 June 2017; Accepted 2 August 2017; Published 12 September 2017

Academic Editor: Jun Liu

Copyright (C) 2017 Xiao-jun Zhu. This is an open access article distributed under the Creative Commons Attribution License, which permits unrestricted use, distribution, and reproduction in any medium, provided the original work is properly cited.

Disconnected piled raft (DPR) foundations are characterized by having no structural connection to a raft. The raft-pile gap is filled with a granular cushion, which creates a more uniform pressure distribution on the raft and reduces the differential settlement. A series of tests has been performed to investigate the load transfer mechanisms of a DPR. The effects of the thickness and stiffness of the cushion and the pile diameter are presented and discussed. A simple failure mode of the cushion is also put forward according to the cushion slip plane obtained by using the digital image correlation technique that tracks the pixels in the images and generates a displacement field. Then a new theoretical analysis has been presented for rigid pile composite foundation. Through comparative studies, it is found that the present method is validated as reasonable by laboratory tests and is in agreement with several current design methods.

\section{Introduction}

In situations where a raft foundation alone does not satisfy the design requirements, it may be possible to enhance the performance of a raft by adding piles, producing what is called a piled raft, where the piles are employed as settlement reducers. In the presence of certain structural/geotechnical conditions, the use of a piled raft has been widely adopted as an effective foundation method for designing high-rise buildings because of the efficiency of piled rafts in (1) increasing the global bearing capacity and (2) reducing the total and differential settlements, as was first proposed by Burland et al. [1]. As mentioned by Poulos [2], piled rafts embody a possible realization of the so-called creep piling design approach defined by Randolph [3], in which piles work under very high loads. The adoption of piled rafts is also associated with interesting economic and environmental benefits: as reported by Huang et al. [4], this design approach has been widely applied in China, to the extent that designing settlementreducing piles for tall buildings is currently mandatory in Shanghai.

When piles are used as settlement reducers, the objective of the piled raft design is to achieve an economic foundation by minimizing the number of piles while fully utilizing their bearing capacity. Then, high bending moments and concentration of the axial stress in the pile head occur in the piled raft. In seismically active zones, if the piles are structurally connected to the raft, high horizontal shear forces and overturning moments may develop in the pile head due to cyclic or dynamic lateral loads. For example, the foundation system of the Rion-Antirion Bridge in Greece $[5,6]$ consists of a gravel bed that limits the shear forces and moments transmitted between the superstructure and the foundation soil. In these cases, the load-carrying capacity of piles may be governed by their structural capacity rather than by their geotechnical capacity. In addition, constraint reactions between the piles of a raft can be reduced by disconnecting the piles from the raft by inserting a layer of compacted granular material called a cushion [7]. The cushion prohibits loads coming from the superstructure from being directly transmitted to the piles; hence, the disconnected piles function as soil reinforcements rather than as pure structure members [8].

In the latter respect, a disconnected piled raft (DPR) is different from a piled raft (PR) because the piles are disconnected from the raft. Several authors have recently 


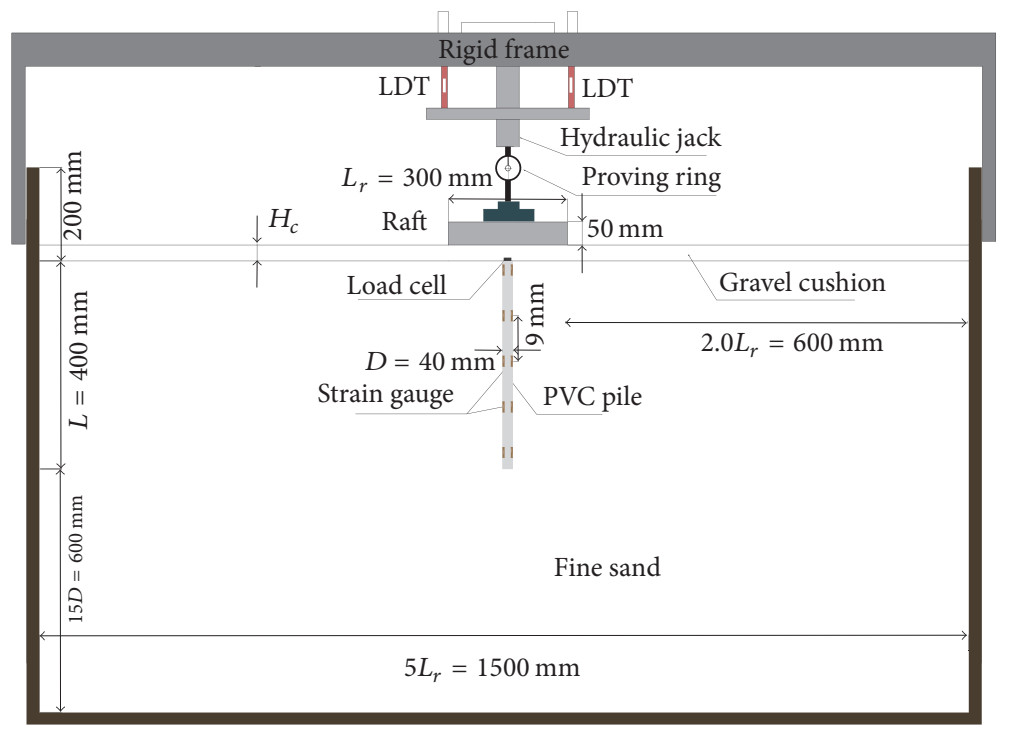

FIgURE 1: Test diagram.

presented the behaviour of a DPR via numerical simulations. Liang et al. $[9,10]$ showed that a cushion made with sandgravel materials plays an important role in mobilizing the bearing capacity of the subsoil and in modifying the load transfer mechanism of piles. Eslami and Malekshah [11] performed elastoplastic analyses to show that the maximum axial stress along piles occurs at different depths depending on the thickness and stiffness of the cushion. Tradigo et al. $[12,13]$ performed $3 \mathrm{D}$ finite element analyses to show that an increase in cushion thickness will reduce the overall settlement/stiffness.

The behaviour of a DPR has also been investigated by performing model experiments. Nakai et al. [14] performed centrifuge model tests to show that the DPR foundation makes a significant contribution to the dynamic soilstructure interaction. Cao et al. [15] and Wong et al. [16] suggested that piles can be disconnected from a raft to overcome the problem of high stress in the piles and raft and that the gap between the raft and unconnected piles can be filled with a cushion of structural fill material. Fioravante and Giretti [17] and Fioravante [18] performed centrifuge tests on a piled raft model to investigate the load transfer mechanisms between a raft and piles in dry dense sand in cases where the piles are either in direct contact with the raft or separated from the raft by a granular cushion.

In this framework, experimental tests have been performed on piled raft models to explore the influence of a gravel cushion that is interposed between a raft and piles. The insertion of a deformable cushion between a raft and pile heads allows downward soil-pile relative displacement, which produces negative skin friction on the upper part of the shaft. Such a mechanism is governed mainly by the stiffness and thickness of the interposed cushion. In the DPR system, piles act as vertical reinforcements of the subsoil and improve its mechanical properties by forming a new composite and stiffer material on which the raft rests $[9,16,18,19]$.
This paper is aimed at investigating the influence of the raft-cushion-soil-pile interactions on the load transfer mechanisms and cushion failure mode of the piled raft foundation based on experimental tests.

\section{Model Tests}

A series of model tests are carried out using the test apparatus shown in Figure 1 to study the failure mode of a cushion in a DPR foundation. The test device is mainly composed of a soil box, loading device, and measuring system. The measuring system consists of strain gauges, a load cell, a data acquisition instrument, a linear displacement transducer (LDT), and a digital camera.

2.1. Test Apparatus. Figure 1 presents a schematic diagram of the test apparatus. The soil container size is $1500 \mathrm{~mm}$ long, $1000 \mathrm{~mm}$ wide, and $1200 \mathrm{~mm}$ high. The front of the box is made of tempered glass, while the remaining four sides are made of steel. The model raft is a $300 \mathrm{~mm}$ long $\left(L_{r}\right), 200 \mathrm{~mm}$ wide $\left(B_{r}\right)$, and $50 \mathrm{~mm}$ thick $\left(t_{r}\right)$ rectangular steel plate characterized by a modulus of elasticity of $E_{r}=$ $3.2 \times 10^{5} \mathrm{MPa}$. The raft can be considered as rigid because the raft-soil stiffness ratio is sufficiently high [20]. Therefore, the settlement of the raft is considered to be uniform in the model test.

2.2. Materials. The experiments were performed using dry fine sand with grains that were $22 \%$ finer than $0.075 \mathrm{~mm}$ and a relative density of $66 \%$, and the granular cushion was modelled using different types of graded gravel. Figure 3 presents the grain-size distribution of the test soil. The properties of the soil in each layer are given in Table 1.

The piles had various diameters, $D$, of $40 \mathrm{~mm}, 60 \mathrm{~mm}$, and $80 \mathrm{~mm}$ and a length, $L$, of $400 \mathrm{~mm}$. The piles were made from a polyvinyl chloride (PVC) pipe with a compressive 
TABLE 1: Properties of the soil in the model test.

\begin{tabular}{lccccc}
\hline Soil type & $D_{50}(\mathrm{~mm})$ & $\gamma(\mathrm{kN} / \mathrm{m})$ & $\varphi\left(^{\circ}\right)$ & $c(\mathrm{kPa})$ & $D_{R}(\%)$ \\
\hline Fine sand & 0.13 & 17.7 & 28.3 & 2 & 66 \\
Coloured sand & 0.11 & 17.5 & 26.6 & 2 & 66 \\
Graded gravel & 2.32 & 18.4 & 36.7 & 0 & 74 \\
Coarse gravel & 4.91 & 17.9 & 41.2 & 0 & 71 \\
Fine gravel & 0.54 & 18.7 & 33.5 & 0 & 69 \\
\hline
\end{tabular}

Note. $D_{50}$ is the effective particle size of soil; $\gamma$ is the unit weight of soil; $\varphi$ is the internal friction angle; $c$ is the cohesion; and $D_{R}$ is the relative density.

modulus of $800 \mathrm{MPa}$. In addition, full and half piles were used in the tests. In the test interpretation, the piles were considered rigid, and their settlements were assumed to be constant with depth. The external layers of the piles were specially treated via mechanical turning, to ensure that the relative roughness was greater than 0.1 , so that the ultimate shear resistance did not depend on pile roughness.

The diameters of the model piles, normalized with respect to particle-size dimension, were greater than 300 . This ratio is larger than the lower limit given by Garnier and Konig [21] $\left(1998 ; D / D_{50}>100\right)$. The main geometrical characteristics of the model and boundary conditions are presented in Figure 1; the ratio between the diameter of the container and the raft side was greater than three, and the distance of the pile tip from the container bottom was always greater than $10 \mathrm{D}$.

The stresses at the pile head and tip were measured by using two load cells positioned at the top and base of each pile. In addition, the pressure of the subsoil was measured by taking the mean value of four load cells positioned on top of the fine sand, as shown in Figure 2. The pile-longitudinal strains in the central pile as a test pile were measured by using five strain gauges, which were attached to the surface of the pile shaft and covered with epoxy resin. The bondedfoil strain gauges were connected in a Wheatstone bridge and gave an accurate measurement of the axial load.

2.3. Test Cases. A total of 9 tests were conducted to discuss the behaviour of the cushion, as shown in Table 2, in which the main characteristics of the tests are presented, and case 1 was used as a reference test. To find the factors affecting the vertical load transfer mechanism, cases 2 through 7 were focused on the gravel cushion. The behaviour of the cushion was investigated for three types of gravel with different internal friction angles and particle sizes, including graded gravel, coarse gravel, and fine gravel. Case 2, case 3 , case 4 , and case 5 were used as reference cases to compare the conditions based on the cushion thickness. Case 6 and case 7 were focused on the effect of the cushion stiffness. In this part, case 2, which involved a graded gravel cushion, was compared with case 6 and case 7 , which involved coarse gravel and fine gravel. Case 8 and case 9 were focused on the effect of the pile diameter. In this part, case 4 , which had a pile diameter of $40 \mathrm{~mm}$, was compared with case 8 and case 9, which had pile diameters of $60 \mathrm{~mm}$ and $80 \mathrm{~mm}$, respectively.

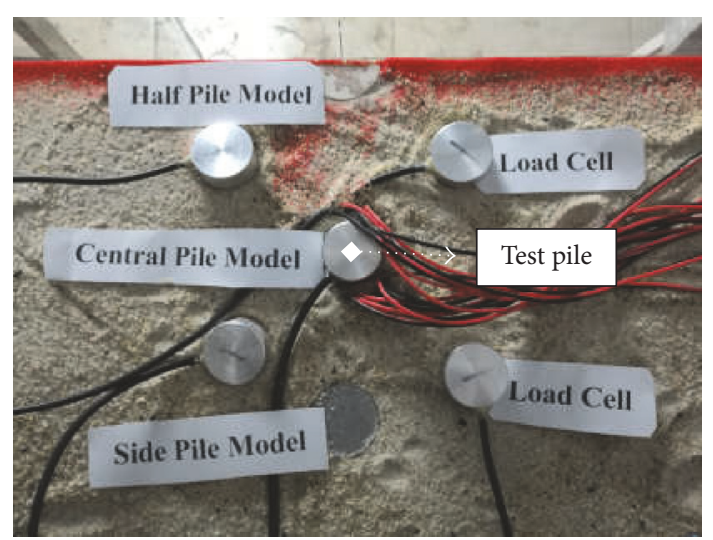

FIgURE 2: Model test apparatus: top view.

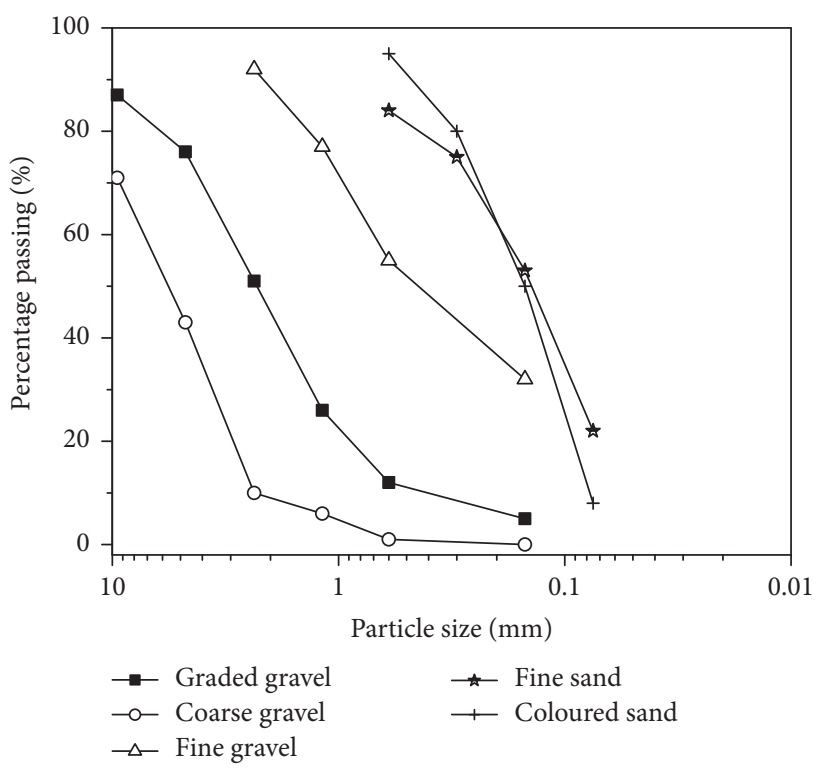

Figure 3: Particle size distributions of soil in the model test.

2.4. Test Procedures. The soil box in the apparatus was filled with fine sand to a height of $1000 \mathrm{~mm}$, and the gravel cushion was laid on the fine sand. The coloured sand was used as a marking line in the soil. The particle size distributions of the soil layers are shown in Figure 3. After completing the gravel cushion, the raft was laid on the cushion, and then a vertical load on the raft was imposed stepwise by using a hydraulic jack. The jacking and loading phases were executed at a constant loading rate with an increment of $400 \mathrm{~N}$, which was measured by the proving ring. For each loading stage, the static load was kept constant for half an hour. Then, the settlement of the raft was obtained by averaging the measurements of the two LDTs that were placed in diametrically opposite positions with respect to the jack, as shown in Figure 1. Meanwhile, the strain on the pile and the soil pressure at the pile head and cushion were collected by the acquisition instrument.

The process of raft sinking was captured using a highresolution camera. Figure 4(a) shows a typical picture of the 
TABLE 2: Test cases.

\begin{tabular}{|c|c|c|c|c|c|}
\hline Test & Cushion type & Number of piles, $n$ & $H_{c}(\mathrm{~mm})$ & $D(\mathrm{~mm})$ & $L(\mathrm{~mm})$ \\
\hline Case 1 & Graded gravel & 0 & 40 & - & - \\
\hline Case 2 & Graded gravel & 3 & 20 & 40 & 500 \\
\hline Case 3 & Graded gravel & 3 & 40 & 40 & 500 \\
\hline Case 4 & Graded gravel & 3 & 60 & 40 & 500 \\
\hline Case 5 & Graded gravel & 3 & 80 & 40 & 500 \\
\hline Case 6 & Coarse gravel & 3 & 40 & 40 & 500 \\
\hline Case 7 & Fine gravel & 3 & 40 & 40 & 500 \\
\hline Case 8 & Graded gravel & 3 & 60 & 60 & 500 \\
\hline Case 9 & Graded gravel & 3 & 60 & 80 & 500 \\
\hline
\end{tabular}

Note. $H_{c}$ is the cushion thickness; $D$ is the pile diameter; and $L$ is the pile length.

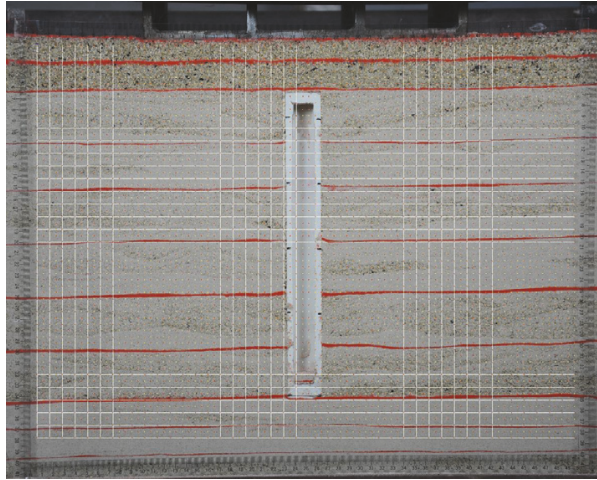

(a)

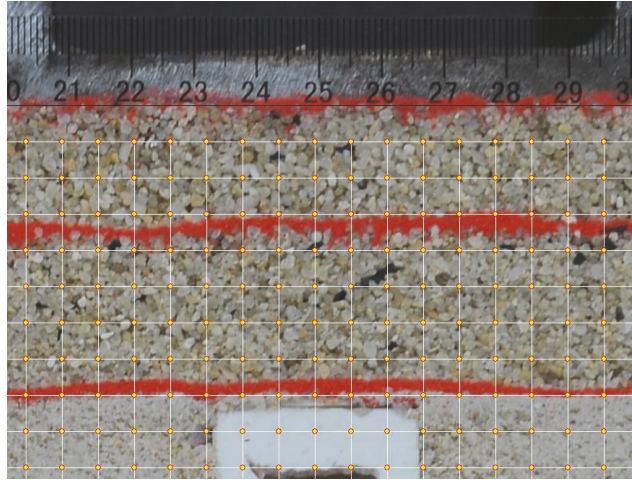

(b)

Figure 4: Digital image correlation: (a) representative photo of the piled raft test with the analysis grid; (b) detailed view of the analysed grid.

test, where the analysis grid has been superimposed onto the photography. The images have a resolution of 8.1 pixels per millimetre. Then, using MATLAB'S toolbox for digital image correlation [22], it is possible to track the movement of the soil and to compute the strain field that occurs in the soil mass.

Digital image correlation (DIC) is a technique used to calculate displacements from a series of consecutive images. In general terms, the technique involves maximizing a correlation coefficient that is determined from the analysis of a subset of pixels. The analysis grid is specified based on the distances and radii of circular track regions, as shown in Figure 4(b). The optimization process generates a mapping function of marker displacements from one image to the next. The precision of this technique depends on the resolution of the pictures, the analysis grid, and the size of the markers. If the markers are too close, noise is incorporated into the results. On the other hand, if the markers are too far apart, the precision of the estimated displacement is reduced. In this case, the picture was $4928 \times 3264$ pixels, the centres of markers were 60 pixels apart, and the radius of each marker was 20 pixels. The grid shown in Figure 4(a) has 6000 markers.

\section{Test Results and Discussion}

The raft load was borne by the pile and fine sand because of the installation of the gravel cushion and then transmitted to the bottom soil layer. During the loading test, each load increment was maintained for approximately half an hour until the deformations of the raft were stable. Therefore, the influence of consolidation on the test results was neglected in the study.

3.1. Load-Settlement Behaviour of DPR. Figure 5(a) presents the load-settlement behaviour of the disconnected piled raft. The curves of the piled rafts had higher gradients than that of the reference test (case 1) because of the pile being under the cushion. Obviously, the settlements increased as the cushion thickness increased and decreased as the pile diameter increased. Compared to the graded gravel cushion, 


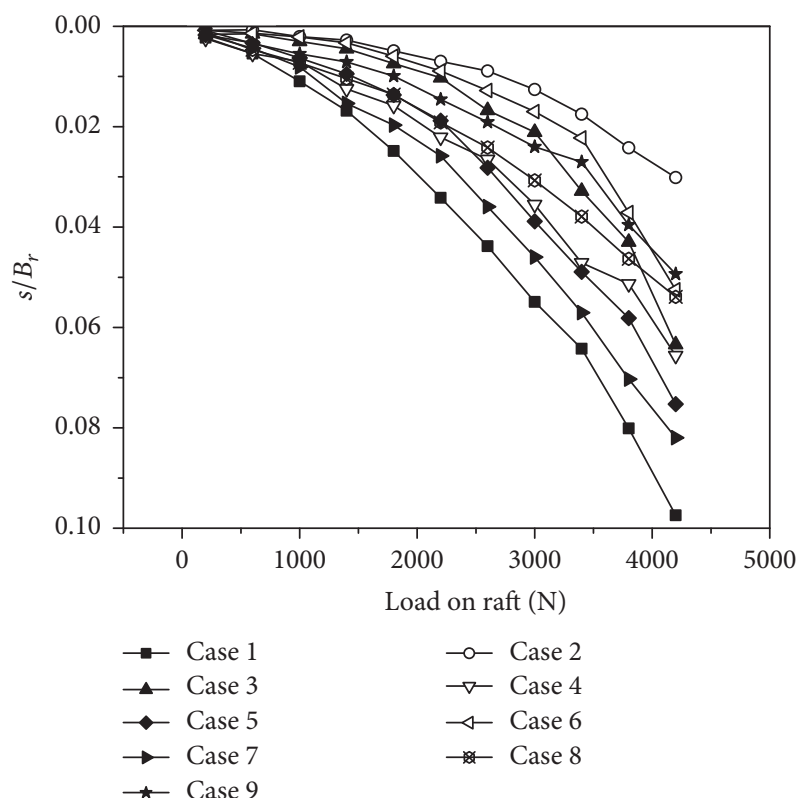

(a)

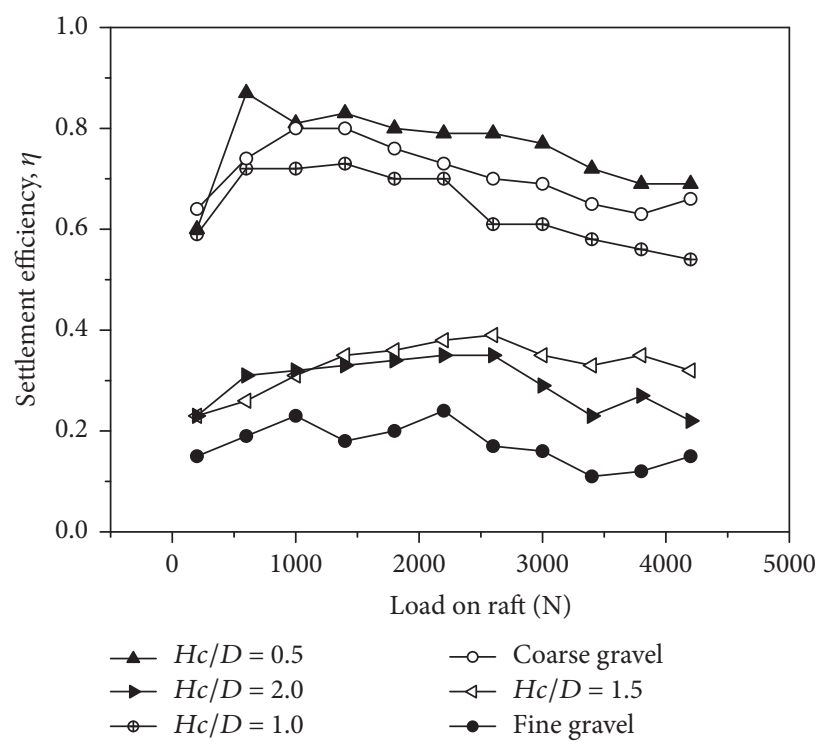

(b)

FIGURE 5: Load-settlement relationships of DPR: (a) load-settlement curve; (b) settlement efficiency.

the settlements increased with fine gravel and decreased with coarse gravel.

The settlement performance of a DPR can be quantified by means of the definition of the following settlement efficiency ratio [17]:

$$
\eta=\frac{w_{r}^{\text {upr }}-w_{r}}{w_{r}^{\text {upr }}}
$$

where $w_{r}^{\text {upr }}$ and $w_{r}$ are the settlements of the unpiled raft and the DPR, respectively. Since $w_{r}^{\text {upr }}>w_{r}$ (and $\left.0 \leq \eta \leq 1\right)$, the larger the value of $\eta$, the more efficient the DPR at a given load level.

The dependence of the settlement efficiency on the vertical load is presented in Figure 5(b). The trends in Figure 5(b) show that the settlement efficiency is approximately constant in the experienced range of displacement and that it depends on the thickness and stiffness of the gravel cushion: $\eta=$ $0.77,0.61,0.35$, and 0.29 for $H_{c} / D=0.5,1.0,1.5$, and 2.0 , respectively; $\eta=0.61,0.69$, and 0.16 for the cushions consisting of graded gravel, coarse gravel, and fine gravel, respectively.

3.2. Stress Concentration Ratio. The variations of the pile-soil stress concentration ratio had nearly identical characteristics in all 8 piled raft tests (Figure 6). As shown in Figure 6(a), for different cushion types, the stress concentration ratio versus the vertical load had the same characteristics. With an increase in the vertical load, the stress concentration ratio increased rapidly; it then increased slowly when the vertical load reached $3000 \mathrm{~N}$, except in case 2 and case 6 . The larger the $H_{c} / D$ ratio, the lower the stress concentration ratio. Case 6 and case 7 showed that the stress concentration ratio decreased with the particle size of the gravel cushion.
A lower stress concentration ratio indicates that a higher percentage of the vertical load on the raft is transferred to the soil surrounding the pile through the gravel cushion.

Figure 6(b) shows the maximum stress concentration ratio of cases 2-5 and cases 8-9 versus the $H_{c} / D$ ratio; it was observed that the stress concentration ratio decreased as the value of $H_{c} / D$ increased. When $H_{c} / D \geq 1.0$, the stress concentration ratio decreased gradually and remained within a nearly constant value range of 10-14.

3.3. Axial Forces in Pile. The axial forces in a pile were calculated based on the measured strains of the piles. The deformation of a pile under the loading condition was assumed to be in the elastic state. Thus, the axial force $N$ in a pile at a certain depth can be calculated as follows: $N=$ $\varepsilon_{a} E_{p} A_{p}$, where $\varepsilon_{a}$ is the average strain of the pile, $E_{p}$ is the elastic modulus of the pile, and $A_{p}$ is the cross-sectional area of the pile. The elastic modulus and cross-sectional area of the pile in our study were $800 \mathrm{MPa}$ and $12.56 \mathrm{~cm}^{2}$, respectively. The average of the measured strains at a certain depth was adopted. There were two strain gauges at certain depths of the pile.

Figure 7 presents the variation of axial forces along the peripheral pile shafts in the tests. The axial forces along the pile shaft were distributed nonlinearly. The distribution patterns of axial forces along the pile shaft were different because of the different cushion thicknesses. As shown in Figure $7(\mathrm{a})$, the axial force at the top of the pile was the largest, and it decreased with increasing depth of the pile shaft.

A pile is loaded partially through its head and partially by means of negative skin friction, which acts on its upper shaft. The pile-soil relative displacement is at a maximum at the pile head and tip and is zero at a certain depth with respect 


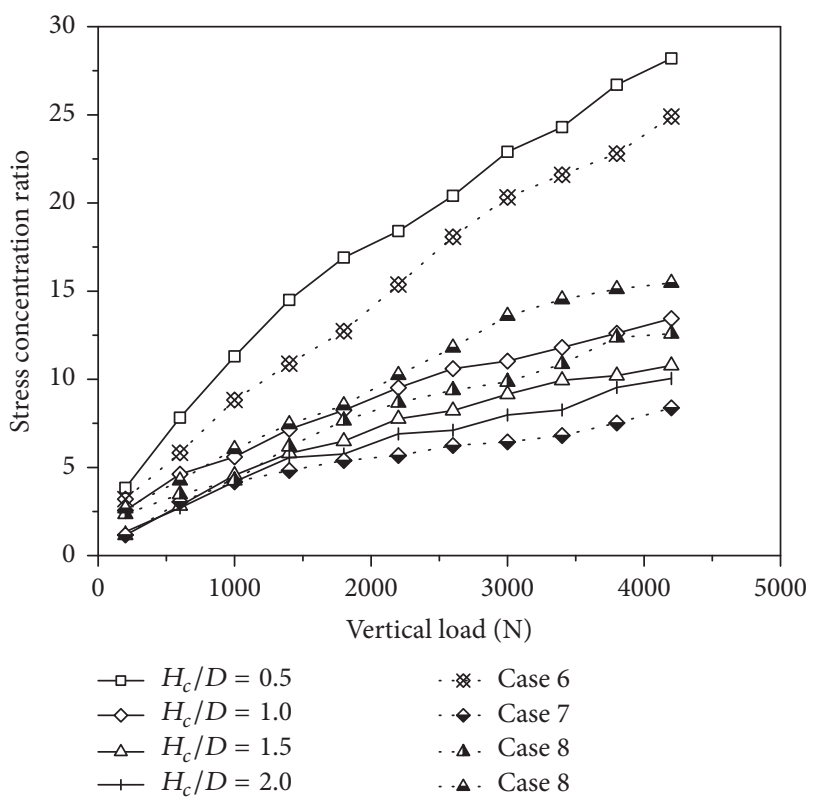

(a)

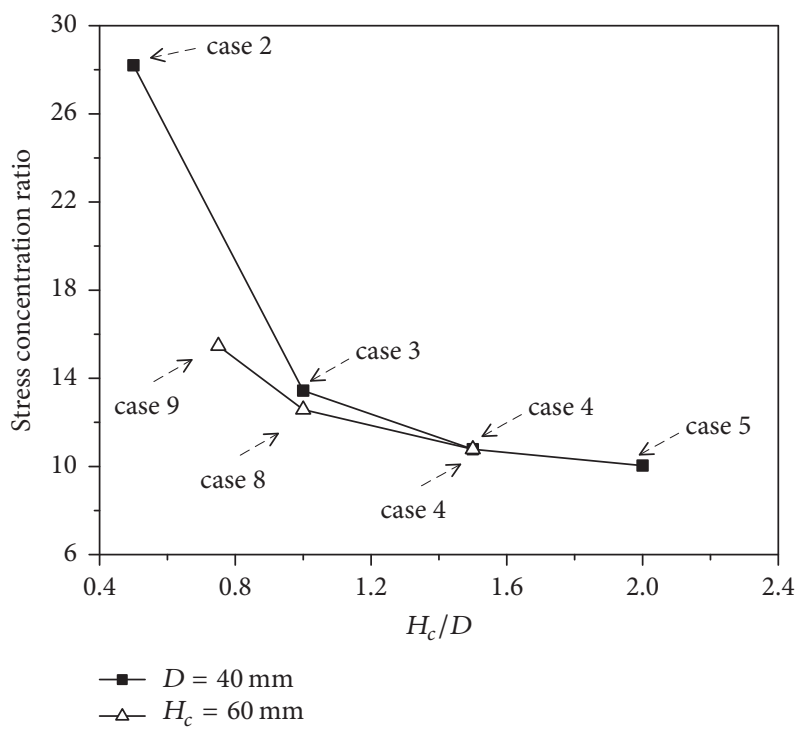

(b)

Figure 6: Pile-soil stress concentration ratio: (a) during load procedure; (b) maximum stress ratio.

to the pile head (neutral plane). As a result, the maximum axial stress of the pile shaft in the downward direction with respect to the pile head was as shown in Figures $7(\mathrm{~b})-7(\mathrm{~d})$. The neutral plane was probably at a depth lower than the midpile at the beginning of the load and then moved downwards as the applied load was increased.

3.4. Soil Displacement Nephogram. This test was performed in 20 stages. Figures 8-9 show the displacements at the end of cases 2-4, cases 6-7, and case 9 inferred using the DIC technique.

The horizontal displacement of soil obtained from the DIC technique is shown in Figure 8. To visualize the soil displacement more easily, colour changes are defined in the colour bar. $-1.4<$ displacement value $<1.4$ was the interval for the 6 cases. The unit of the coordinates was $\mathrm{mm}$. The horizontal soil displacement was concentrated at the top of the pile and then developed along both sides, with the pile serving as the axis. In addition, the soil particles were ejected from the pile head.

The common behaviour in the case was a cone-shaped area of high density at the pile head, as shown in Figure 9. From the same figure, it was seen that there was a significant change in the density from higher to lower, forming two independent sectors divided by the pile shaft. It was seen that the density at the top of the pile head and that under the raft were greater because the soil was compacted as a result of the settlement of the raft. The density at the edge of sectors decreased because of soil dilatancy as a result of the settlement of the subsoil. The shear plane and dilatancy occurred at the edge of sectors. This resulted in a decrease in the density of soil in the fan-shaped area, which was defined by low-density areas. The high-density areas above the pile head represented the soil compaction process.

3.5. Settlement Distribution of Gravel Cushion. The settlement of the gravel cushion was determined based on the soil displacement nephogram, and the displacement curve is shown in Figure 10. The legend of the graph indicates the distance from the bottom of the raft. As seen, the curve shape was similar to a saddle shape, and the settlement of soil on top of the pile head was relatively low, while that beside the pile was much greater, and differential settlement occurred. Figure 10 also shows that the soil displacement outside the raft was negative as a result of the uplift of soil beside the raft.

Figure 10(a) shows the settlement of the gravel cushion for case 2; the pile-soil relative displacement increased as the distance from the bottom of the raft increased. This increase was due to the effect of the compression of the raft and pile. Figures 10(b)-10(f) show the settlement of the gravel cushion for cases 3-4, cases 6-7, and case 9. As seen, at a distance of $1.0 \mathrm{~cm}$, no apparent differential settlement occurred. When the distance from the raft was $2.0 \mathrm{~cm}$ or more, the pile-soil relative displacement was formed, which increased as the cushion thickness increased.

\section{A New Cushion Failure Mode}

A fan-shaped shear plane occurred at the cushion and a coneshaped area occurred at the pile head according to the results of tests that involved the DIC technique. In addition, the slip plane of the cushion could be determined according to these characteristics. A simple failure mode of the cushion was put forward, as shown in Figure 11. 


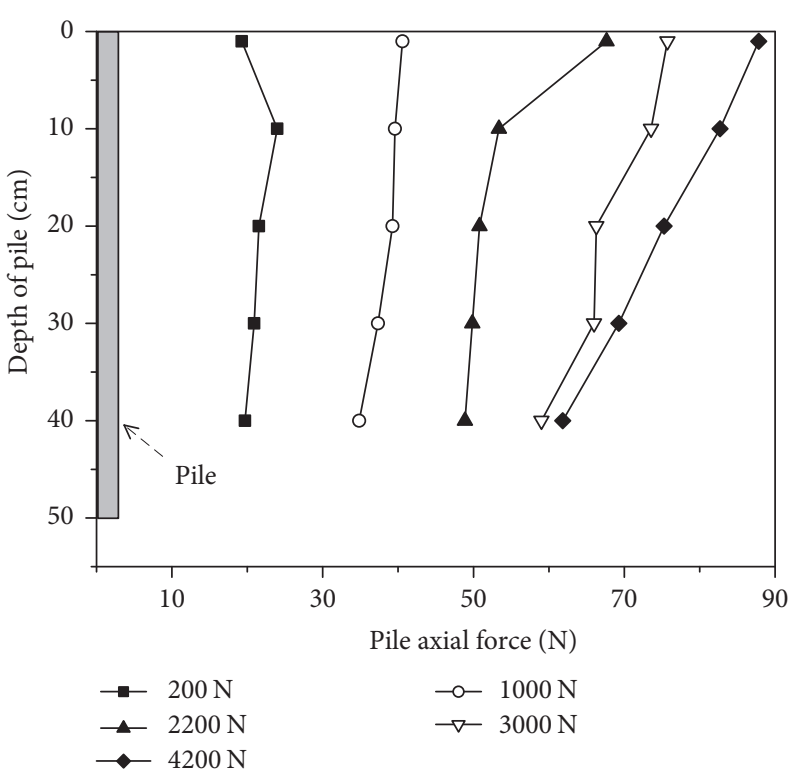

(a)

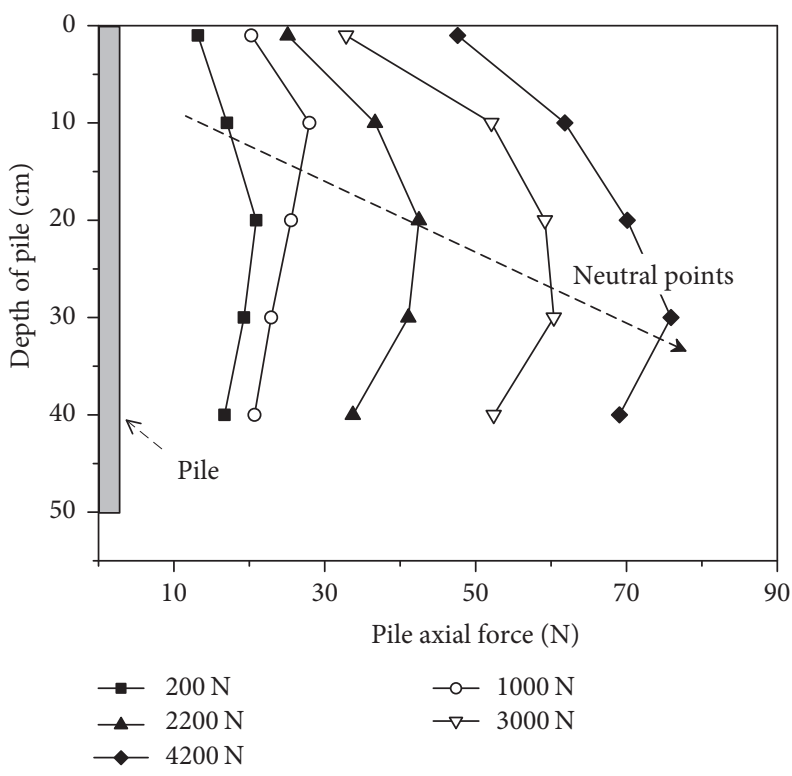

(c)

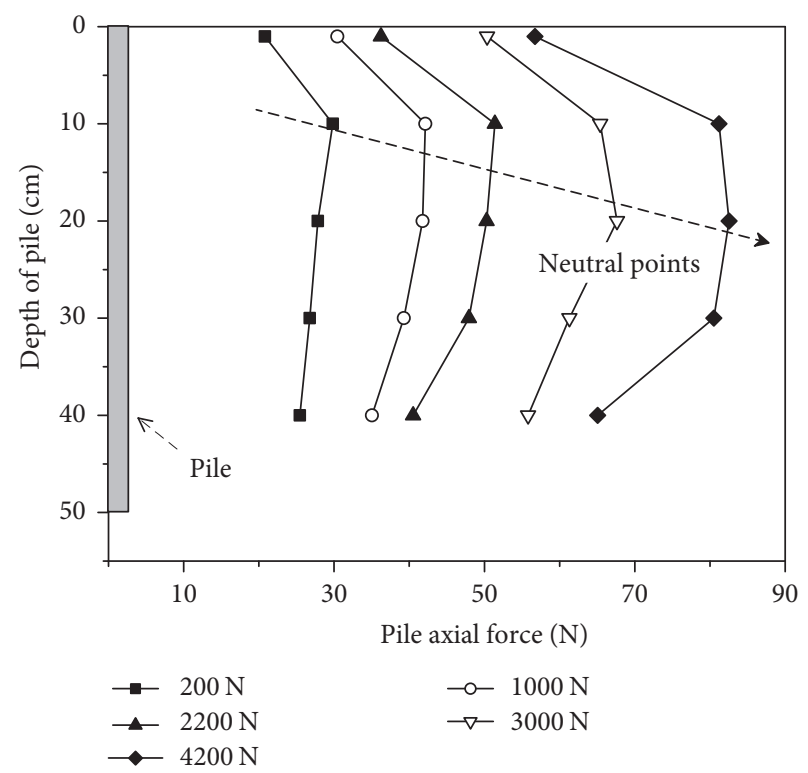

(b)

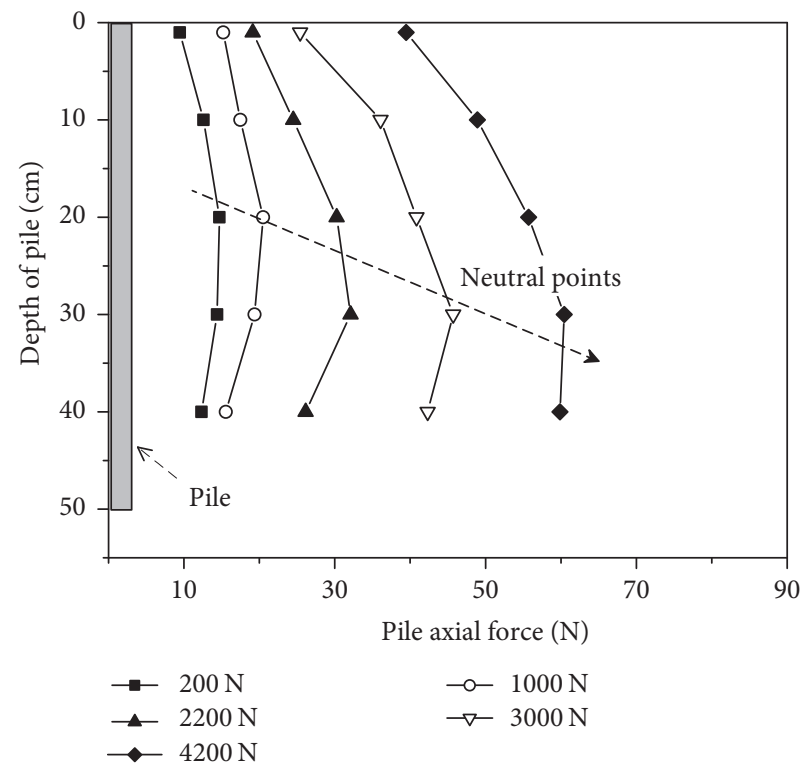

(d)

FIGURE 7: Variation of axial forces along pile shaft: (a) case 2; (b) case 3; (c) case 4; (d) case 5.

4.1. Establishment of the Cushion Failure Mode. The cushion failure mode can be divided into three parts. The cone-shaped area (area I) at the pile head is the active earth pressure zone. In this area, the cushion moves to the pile top, which is in the passive state, and the pile can be considered as equivalent to a retaining wall. Area II is the transition zone, and the shear zone is formed along the pile top core in this area. The soil of area II slides along the shear zone and compresses the soil in area III. Area III is the passive earth pressure zone. The envelope curve of the three zones forms the slip line, as shown by curves ACDE and ABGF in Figure 11.

The graphical method for determining the cushion failure mode is put forward according to the literature [23]. Draw a right triangle with a proper scale and make the acute angle $\left(\angle B_{1} A_{1} C_{1}\right.$ ) equal to the internal friction angle of the gravel. Then, draw a line $B_{1} D_{1}$ perpendicular to hypotenuse $A_{1} C_{1}$. Finally, draw three concentric circles from centre $C_{1}$ with radii of $C_{1} D_{1}, C_{1} B_{1}$, and $C_{1} A_{1}$. The smallest, middle, and largest circles are, respectively, plane circle I, vertex circle II, and pole circle III, as shown in Figure 12.

The boundaries of zone I and zone III are determined by using the graphical method. First, draw a chord $M N$ that is tangent to the plane circle at the point $P$ and parallel to the hypotenuse $A_{1} C_{1}$. Afterwards, extend the radius $C_{1} P$, with the vertex circle and pole circle intersecting at points $F_{1}$ and $G_{1}$, respectively. In addition, retract the radius $C_{1} P$, 


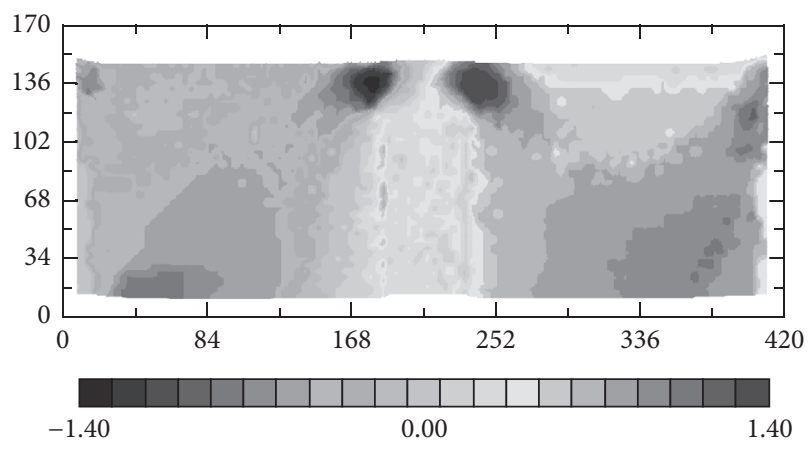

(a)

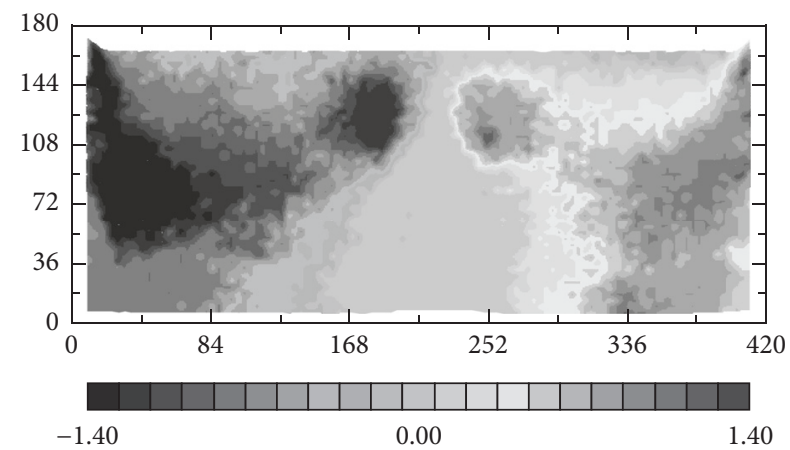

(c)

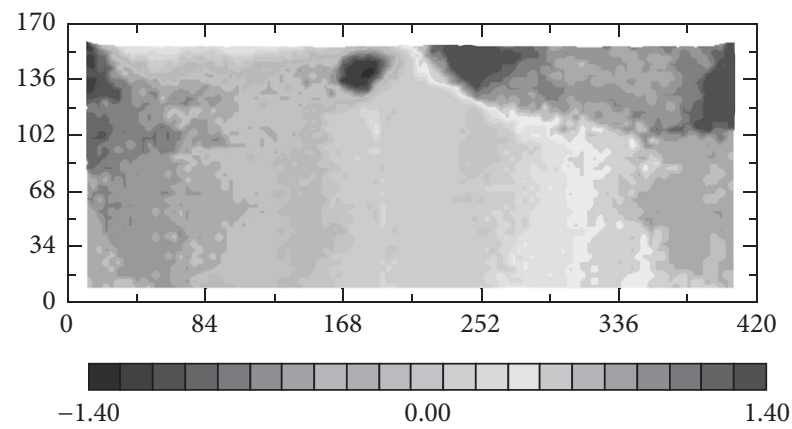

(e)

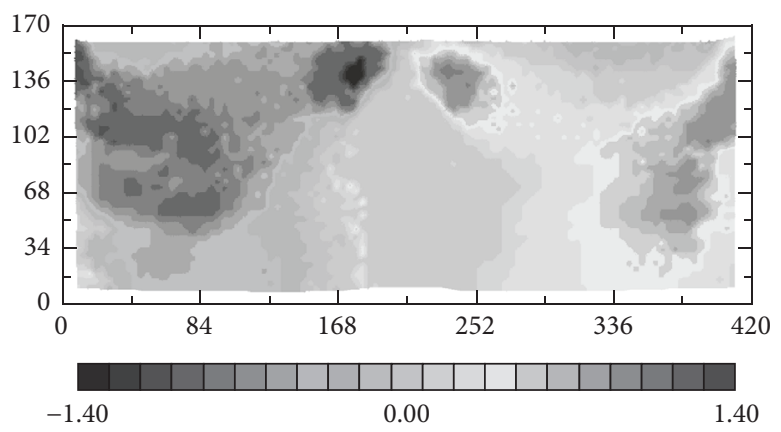

(b)

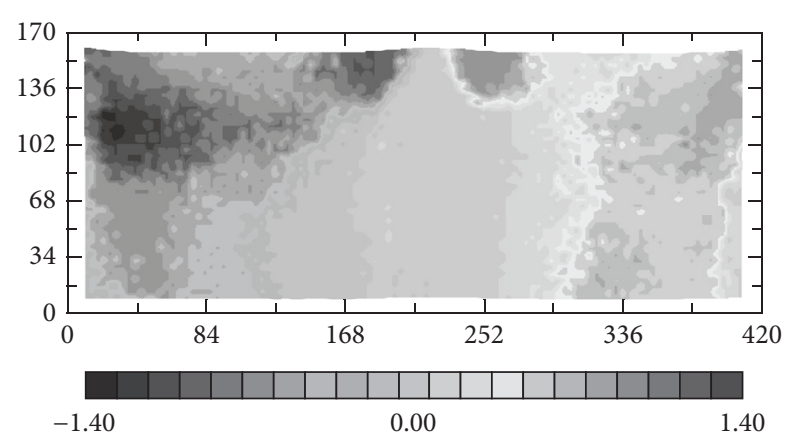

(d)

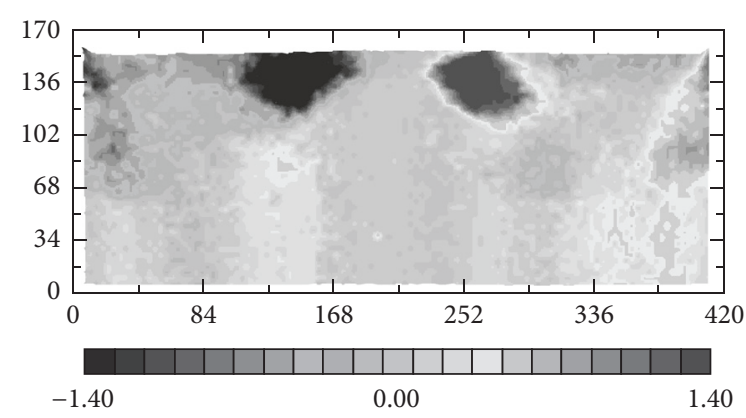

(f)

Figure 8: Horizontal displacement of soil: (a) case 2; (b) case 3; (c) case 4; (d) case 6; (e) case 7; (f) case 9.

with the vertex circle intersecting at point $E_{1}$. Line $M N$ can be analogous to the pile head. Then, the sliding direction of zone $I$ is given by the lines $M E_{1}$ and $N E_{1}$. In addition, the sliding direction of zone II is given by the lines $M F_{1}$ and $N F_{1}$.

Line $C D$ is assumed to be a logarithmic spiral line, as shown in Figure 11. The length of line $A D$ can be calculated as follows:

$$
\frac{r_{A C}}{r_{A D}}=e^{\theta \tan (\varphi)},
$$

where $r_{A C}$ is the length of $A C, r_{A D}$ is the length of $A D, \theta$ is the angle between $A D$ and $A C$, and $\varphi$ is the internal friction angle of the gravel.

Draw the line $D E$ parallel to $N F_{1}$ to intersect with the gravel surface at the point $E$. The boundary of zone III is given by the lines $D A$ and $D E$. Link points $C$ and $D$ using a smooth curve, and make line $C D$ a logarithmic spiral line. Lines $A C$ and $A D$ are the radii of the logarithmic spiral line
$C D$. Therefore, the boundary of zone II is given by lines $A C$ and $A D$.

The shape of the cushion failure mode corresponds to the characteristic circle. In addition, the angles in the failure mode can be calculated based on the characteristic circle; angle $B A C$ is equal to $\pi / 2-\varphi$, angle $E A D$ is equal to $\pi / 4-\varphi / 2$, and angle $C A D$ is equal to $\varphi$.

4.2. Theoretical Analysis of the Cushion Failure Mode. In developing the present method, the following simplifications were used:

(a) The gravel cushion is homogeneous, isotropic, and cohesionless.

(b) The gravity of the gravel cushion is ignored.

(c) The pile is sufficiently rigid and undergoes insignificant deformation. 


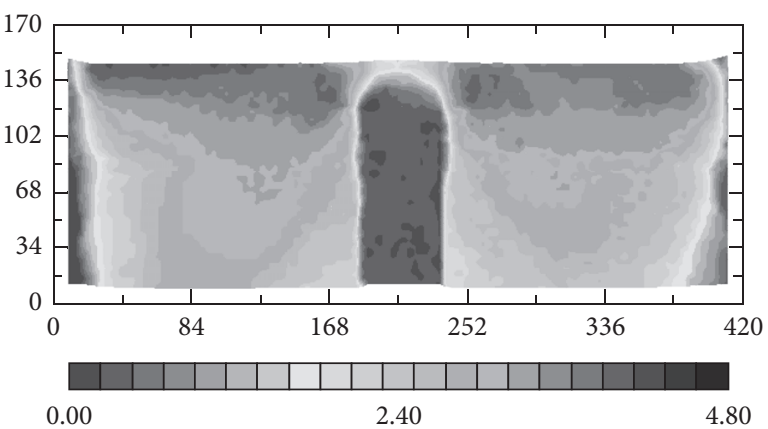

(a)

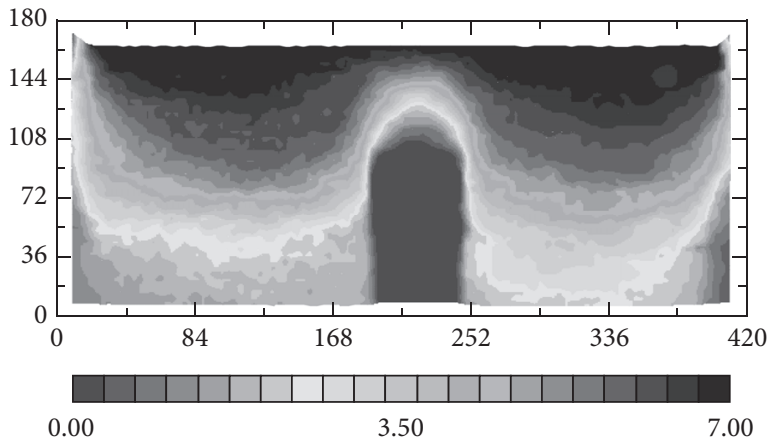

(c)

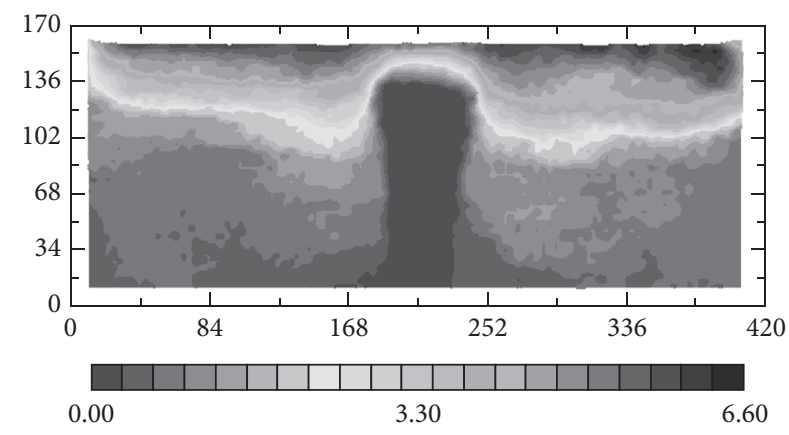

(e)

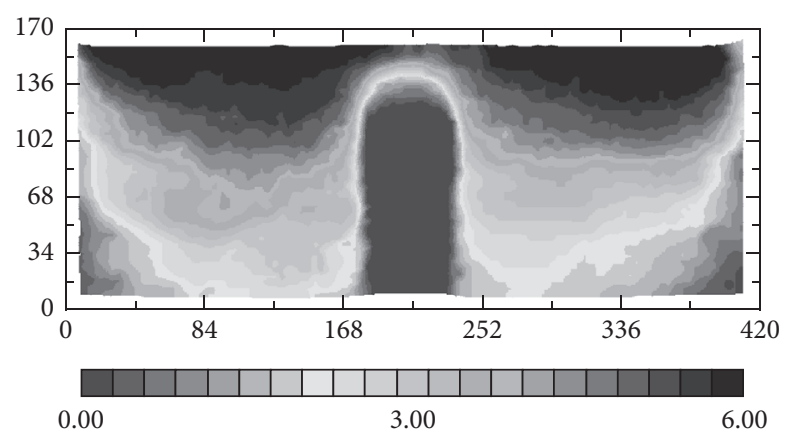

(b)

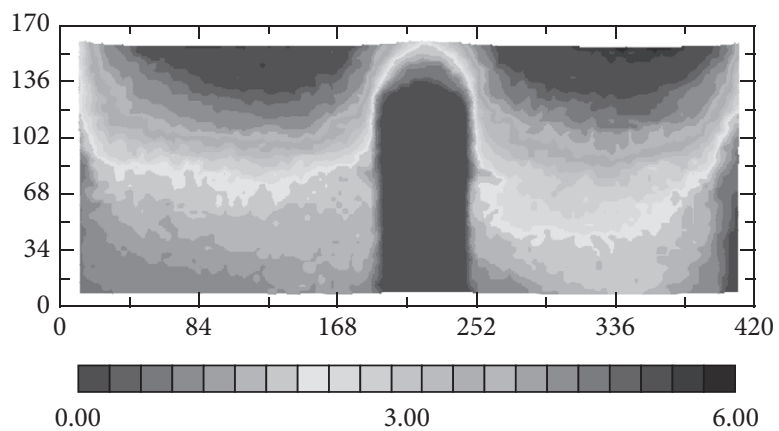

(d)

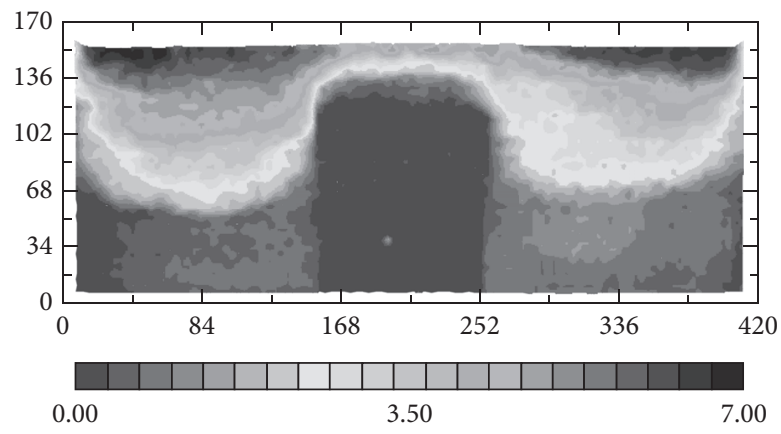

(f)

FIgURE 9: Vertical displacement of soil: (a) case 2; (b) case 3; (c) case 4; (d) case 6; (e) case 7; (f) case 9.

(d) There is no friction between the pile and the gravel cushion.

(e) The gravel cushion undergoes general shear failure.

The cushion failure mode can be simplified to the shape shown in Figure 13 because of the symmetry property of the stress and shape. Area $A O C$ is the active earth pressure zone, while area $A D H$ is the passive earth pressure zone. A formula for determining the stress at the pile head and in the soil between the piles and the pile-soil stress ratio can be derived based on the plastic equilibrium theory.

According to assumptions, the resultant force action point of both the pressure and shear on the logarithmic spiral line $C D$ is point $A$. Take point $A$ as the centre of the moment; then, the moment of the stress on the pile head is

$$
M_{Q}=\frac{Q}{2} \cdot\left(\frac{d}{2}\right)^{2}=\frac{d^{2}}{8} Q,
$$

where $M_{\mathrm{Q}}$ is the moment of the stress on the pile head, $d$ is the pile diameter, and $Q$ is the stress on the pile head.

The moment of the active earth pressure is

$$
M_{p_{1}}=p_{1} \cdot \frac{1}{2} \cdot\left(\frac{d}{2} \cot (\alpha)\right)^{2}=\frac{d^{2}}{8} \cot ^{2}(\alpha) p_{1},
$$

where $M_{p_{1}}$ is the moment of the active earth pressure, $p_{1}=$ $Q \tan ^{2}(\alpha)$ is the active earth pressure, and $\alpha=\pi / 4-\varphi / 2$ is the angle of $E A D$.

The moment of the passive earth pressure is

$$
M_{p_{2}}=p_{2} \cdot \frac{1}{2} \cdot\left(\frac{d}{2} e^{\varphi \tan (\varphi)}\right)^{2}=\frac{d^{2}}{8} e^{2 \varphi \tan (\varphi)} p_{2}
$$

where $M_{Q}$ is the moment of the passive earth pressure and $p_{2}=q \cot ^{2}(\alpha)$ is the active earth pressure. 

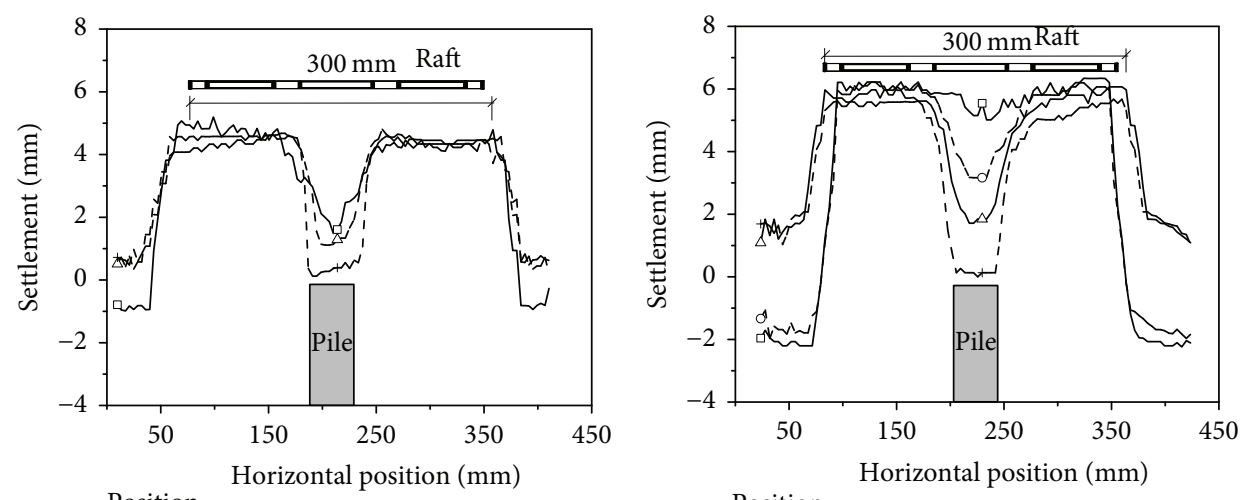

Position

$$
\begin{aligned}
& \multimap-0.5 \mathrm{~cm} \\
& -\Delta-1.0 \mathrm{~cm} \\
& -+-2.0 \mathrm{~cm}
\end{aligned}
$$

(a)

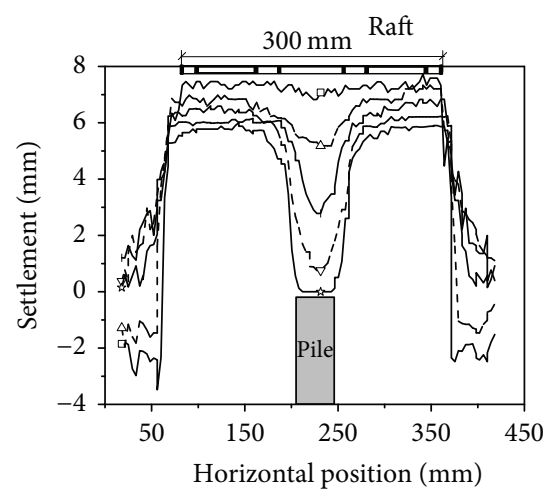

Position

$$
\begin{array}{ll}
\multimap-1.0 \mathrm{~cm} & \multimap 3.0 \mathrm{~cm} \\
-\circ-2.0 \mathrm{~cm} & -+-4.0 \mathrm{~cm}
\end{array}
$$

(b)

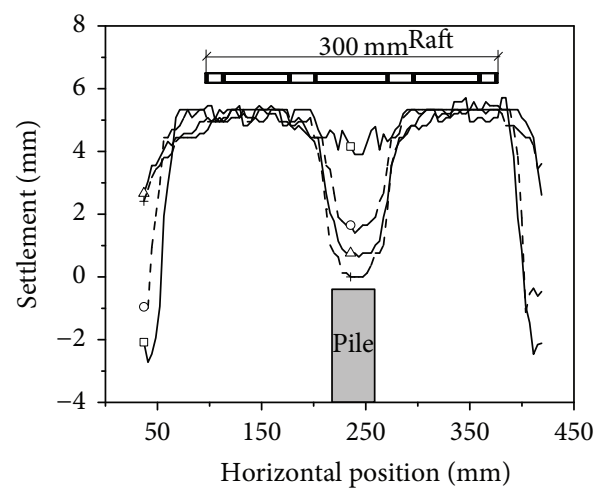

Position

$\rightarrow-1.0 \mathrm{~cm} \quad-\nabla-4.0 \mathrm{~cm}$

$-\Delta-2.0 \mathrm{~cm} \quad \rightarrow \quad 5.0 \mathrm{~cm}$

$+3.0 \mathrm{~cm}$

(c)

Position

$\rightarrow 1.0 \mathrm{~cm} \quad \longrightarrow 3.0 \mathrm{~cm}$

$-\circ-2.0 \mathrm{~cm}$

$-+-4.0 \mathrm{~cm}$

(d)

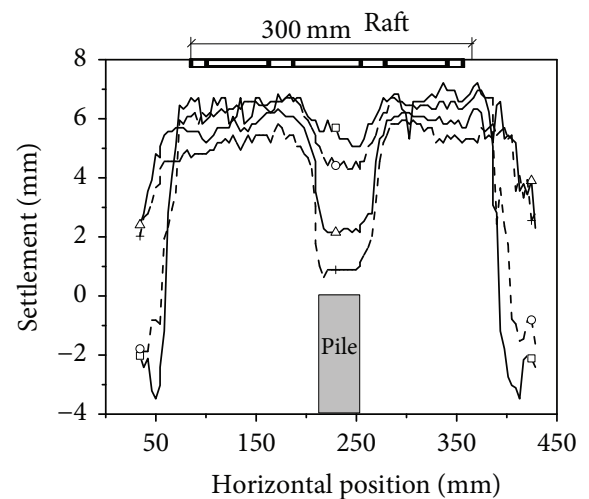

Position

$\rightarrow 1.0 \mathrm{~cm} \quad \rightarrow 3.0 \mathrm{~cm}$

$-0-2.0 \mathrm{~cm} \quad-+-4.0 \mathrm{~cm}$

(e)

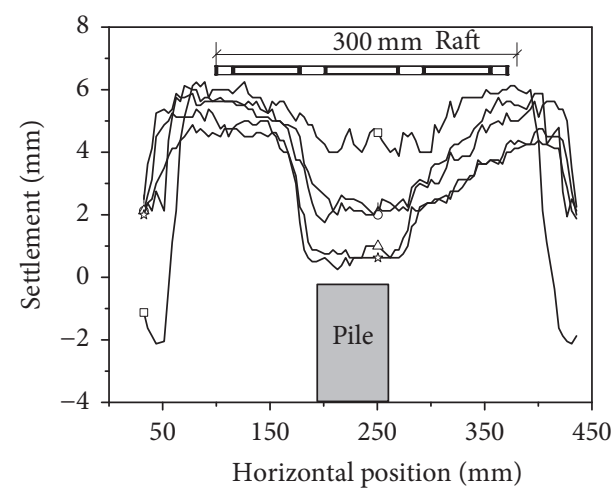

Position

$$
\begin{aligned}
& \square-1.0 \mathrm{~cm} \quad \longrightarrow 4.0 \mathrm{~cm} \\
& \multimap 2.0 \mathrm{~cm} \quad \longrightarrow 5.0 \mathrm{~cm} \\
& \square-0.0 \mathrm{~cm}
\end{aligned}
$$

(f)

FIGURE 10: Settlement of gravel cushion: (a) case 2; (b) case 3; (c) case 4; (d) case 6; (e) case 7; (f) case 9. 


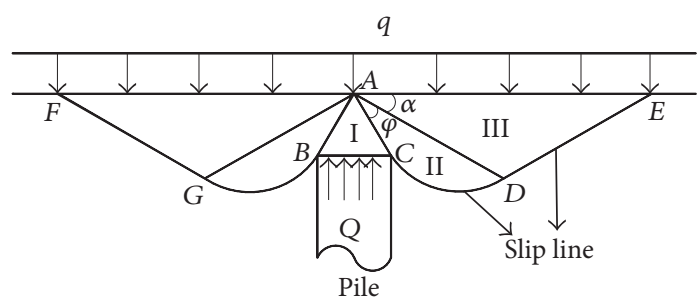

FIgURE 11: Cushion failure mode.

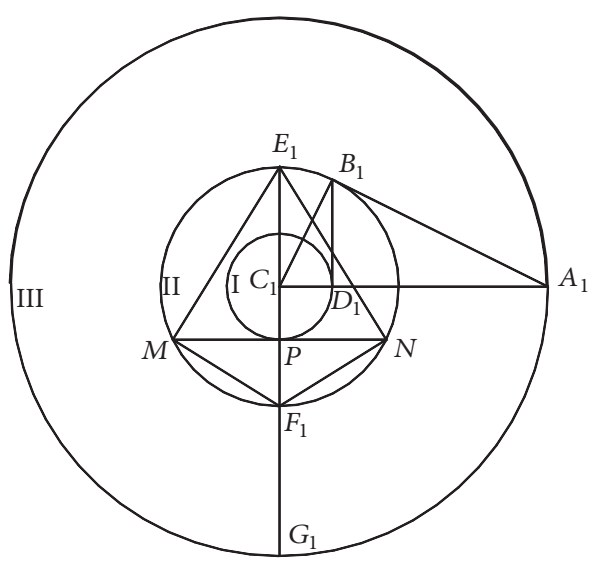

FIGURE 12: The characteristics of the circle.

The moment of the pressure under the raft is

$$
\begin{aligned}
M_{q} & =q \cdot \frac{1}{2} \cdot\left(\frac{d \cot (\alpha)}{2} e^{\varphi \tan (\varphi)}\right)^{2} \\
& =\frac{d^{2}}{8} \cot ^{2}(\alpha) e^{2 \varphi \tan (\varphi)} q,
\end{aligned}
$$

where $M_{q}$ is the moment of the pressure under the raft and $q$ is the pressure under the raft.

The moment balance equation of point $A$ is

$$
\sum M_{A}=M_{Q}+M_{p_{1}}-M_{p_{2}}-M_{q}=0,
$$

where $M_{A}$ is the resultant moment of point $A$.

Substituting (3) (6) into (7), the stress on the pile head is obtained:

$$
Q=\cot ^{2}(\alpha) e^{2 \varphi \tan (\varphi)} q
$$

The overall equilibrium requires that

$$
q+\gamma H_{c}=m Q+(1-m) \sigma_{s},
$$

where $\gamma$ is the gravity of the gravel cushion, $H_{c}$ is the thickness of the cushion, $\sigma_{s}$ is the earth pressure between piles, and $m$ is the area replacement rate of a pile.

Then, the pile-soil stress ratio is given by

$$
n=\frac{Q}{\sigma_{s}}=\frac{(1-m) \cot ^{2}(\alpha) e^{2 \varphi \tan (\varphi)} q}{q+\gamma H_{c}-m \cot ^{2}(\alpha) e^{2 \varphi \tan (\varphi)} q},
$$

where $n$ is the pile-soil stress ratio.

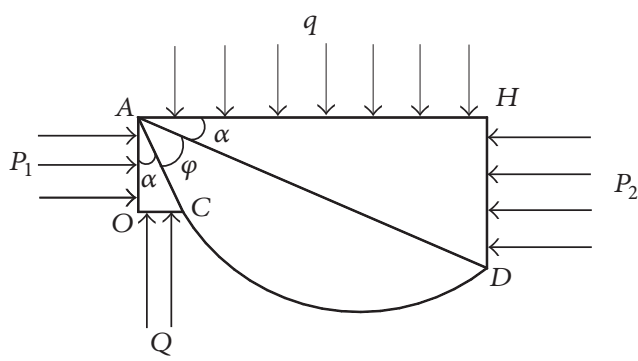

FiguRE 13: Solution to the cushion failure mode.

Equations (2) (10) were deduced under the assumption of general shear failure of the cushion. According to this precondition, the thickness of the cushion should be at least $d / 2 \cdot \cot (\alpha)$.

\section{Comparison Results}

5.1. Comparison with Laboratory Experiments. The laboratory experiments described in Section 2 are used to check the validity of the proposed method. The cushion gravel properties and the dimensions of the piles in the experiments are detailed in Tables 1 and 2, respectively. The areas of the pile and raft are $31.4 \mathrm{~cm}^{2}$ and $600 \mathrm{~cm}^{2}$, respectively, and the area of the soil between piles is $568.6 \mathrm{~cm}^{2}$, then the value of parameter $\mathrm{m}$ is $5.23 \%$.

According to Section 4, the thickness of the cushion should be at least $d / 2 \cdot \cot (\alpha)$. Therefore, the measured data of case 3 , case 4 , and case 7 is selected for comparison with the computation results, as shown in Table 3 . And the internal friction angles of the gravel $\varphi$ of case 3, case 4, and case 7 are $36.7,36.7$, and 33.5 respectively. The $\alpha$ value could be calculated by the formula $\alpha=\pi / 4-\varphi / 2$.

When the cushion is filled with graded gravel and coarse gravel, the calculated results of the proposed method and the measured results are very close. The calculated results of case 7 are on the high side because the settlement curve of case 7 undergoes a steep drop, and the cushion failure mode is local shear failure. Therefore, the vertical stress on the pile has the phenomenon of stress focus. In other words, the proposed method is reasonable.

5.2. Comparison with Several Current Design Methods. To verify the proposed method again, the results of another embankment project, calculated using the present method, are also compared with computed values from several existing design methods proposed by Abusharar et al. [24], Low et al. [25], BS8006 [26], and Guido et al. [27]. The geometry of the embankment and the design parameters used in the present case study are obtained from Chen et al. [28] and Abusharar et al. [24]. They are as follows: pile cap-width $=1.13 \mathrm{~m}$; embankment fill-height $=4.52 \mathrm{~m}$; unit weight $=$ $20 \mathrm{kN} / \mathrm{m}^{3}$, and internal friction angle $=30^{\circ}$. A surcharge of $12 \mathrm{kPa}$ is used throughout unless otherwise specified. No partial factors of safety are applied to the design parameters. The results obtained from several current design methods are 
TABLE 3: Comparison of measured data and computation results.

\begin{tabular}{lcccc}
\hline \multirow{2}{*}{ Test } & \multicolumn{2}{c}{ Measured values $(\mathrm{kPa})$} & \multicolumn{2}{c}{ Calculated values $(\mathrm{kPa})$} \\
& Vertical stress on pile & Stress concentration ratio & Vertical stress on pile & Stress concentration ratio \\
\hline Case 3 & 703 & 13.44 & 721.8 & 12.9 \\
Case 4 & 1254 & 24.9 & 1197.3 & 26.1 \\
Case 7 & 604 & 8.38 & 525.5 & 8.7 \\
\hline
\end{tabular}

TABLE 4: Comparison of measured data and computation results.

\begin{tabular}{lccccc}
\hline \multirow{2}{*}{ Parameter } & \multirow{2}{*}{ Present method } & \multicolumn{4}{c}{ Without geosynthetics } \\
& & Low et al. (1994) & BS8006 (1995) & Guido et al. (1987) & Abusharar et al. (2009) \\
\hline Vertical stress on pile (kPa) & 65.88 & 70.92 & 71.83 & 63.05 & 69.30 \\
Stress concentration ratio & 2.69 & 4.89 & 2.07 & 3.02 & 3.38 \\
\hline
\end{tabular}

compared with the results obtained from the present method and summarized in Table 4.

The results show that the methods of Low et al. [25] and BS8006 [26] overpredict the vertical stress on the pile compared to the method of Guido et al. [27] and the present method because the methods of Low et al. [25] and BS8006 [26] consider the reaction of the geosynthetics. Because the present method and the methods of BS8006 [26] and Guido et al. [27] do not consider the support of the subground by the geosynthetics, their predictions of the stress concentration ratio are close. It can be noted that the prediction results of the vertical stress on the pile of the present method are in good agreement with the results of the methods of Guido et al. [27] and Abusharar et al. [24].

\section{Conclusions}

In this paper, an experimental and theoretical study of the cushion failure mode of a rigid pile foundation was presented based on the results of eight laboratory tests. The focus was on the thickness and gradation of a gravel cushion and the pile diameter.

The experimental procedure consisted of reproducing the cushion failure mode, with a high-resolution camera used to track the experience. The displacement field in the soil was inferred using the digital image correlation (DIC) technique, which tracks the pixels in images and generates a displacement field. Moreover, to discuss the load transfer mechanisms of a composite foundation, five strain gauges attached to the pile, five earth pressure cells, and two displacement transducers were instrumented in the model tests. The main conclusions of this study are as follows:

(1) The settlements of the raft increased with the cushion thickness and decreased with the pile diameter. In addition, the pile-soil stress concentration ratio decreased with the $H_{c} / D$ ratio and with the particle size of the gravel cushion.

(2) Negative friction resistance of the pile shaft occurred in cases 3-5 because the gravel cushion at the top of each pile had a sufficient thickness. The neutral plane of the pile shaft moved down as the vertical load increased. The neutral plane was probably at a depth lower than the mid-pile at the beginning of the load and then moved downwards as the applied load was increased.

(3) The soil displacement field was reproduced by using the DIC technique. It was seen that a fan-shaped shear plane occurred at the cushion and that a cone-shaped area occurred at the pile head. In addition, a shear plane occurred at the edge of sectors because the density at the edge of sectors was decreased due to soil dilatancy as a result of the settlement of the subsoil.

(4) A simple cushion failure mode was put forward according to the slip plane of the cushion. Then, a new theoretical analysis was presented for a rigid pile composite foundation. The results of the proposed methods were verified by laboratory tests results.

(5) A comparison of the amount of vertical stress on a pile predicted by the present method to those of the current design methods showed good agreement with the results of Guido et al. [27] and Abusharar et al. [24]. As for the presented method, the values of the stress concentration ratio predicted by the methods of BS8006 [26] and Guido et al. [27] were close because these methods do not consider the support of the subground by the geosynthetics.

In this study, all the laboratory tests were conducted using rigid piles and a gravel cushion. In future research, experiments with various cushion soils and foundation soils and with flexible piles should be studied to reproduce the cushion failure mode. In addition, further research involving a full-scale test or a centrifuge model test is required and would be useful for accurately investigating the validity of the present method.

\section{Conflicts of Interest}

The author declares that he has no conflicts of interest.

\section{Acknowledgments}

This study was supported by the National Program on Key Basic Research Project of China (Project no. 2013CB036304), Nature Science Foundation of Jiangsu Province of China (Project no. BK20170509), and Natural Science Foundation 
for Colleges and Universities in Jiangsu Province (Project no. 15KJB580013).

\section{References}

[1] J. Burland, B. Broms, and V. De Mello, "Behaviour of foundations and structures," in Proceedings of the 9th International Conference on Soil Mechanics and Foundation Engineering (ICSMFE '77), vol. 2, pp. 495-546, Tokyo, Japan, 1977.

[2] H. G. Poulos, "Methods of analysis of piled raft foundations-a report prepared on behalf of Technical Committee TC18 on piled foundations," Tech. Rep., International Society of Soil Mechanics and Geotechnical Engineering, London, UK, 2001.

[3] M. Randolph, "Design methods for pile groups and piled rafts," in State of the Art Report: 13th International Conference of Soil Mechanics and Foundation Engineering, New Delhi, 1994.

[4] M. Huang, F. Liang, and Z. Li, "Recent advances in the analysis of pile foundation in China," in Advances in Deep Foundations, Y. Kikuchi, J. Otani, M. Kimura, and Y. Morikawa, Eds., pp. 115124, Taylor \& Francis, London, UK, 2007.

[5] J. Garnier and A. Pecker, "Use of centrifuge tests for the validation of innovative concepts in foundation engineering," in Proceedings of the 2nd International Conference of Earthquake Geotechnical Engineering, pp. 431-439, 1999.

[6] A. Pecker, "Design and construction of the rion antirion bridge," in Geotrans, pp. 216-240, 2004.

[7] N. Mattsson, A. Menoret, C. Simon, and M. Ray, "Case study of a full-scale load test of a piled raft with an interposed layer for a nuclear storage facility," Géotechnique, vol. 63, no. 11, pp. 965-976, 2013.

[8] H. G. Poulos, "Piled raft foundations: design and applications," Géotechnique, vol. 51, no. 2, pp. 111-113, 2001.

[9] F.-Y. Liang, L.-Z. Chen, and X.-G. Shi, "Numerical analysis of composite piled raft with cushion subjected to vertical load," Computers and Geotechnics, vol. 30, no. 6, pp. 443-453, 2003.

[10] F. Liang, J. Li, and L. Chen, "Optimization of composite piled raft foundation with varied rigidity of cushion," in Foundation Analysis and Design: Innovative Methods, pp. 29-34, 2006.

[11] A. Eslami and S. S. Malekshah, "Analysis of non-connected piled raft foundations (NCPRF) with cushion by finite element method," Computational Methods in Civil Engineering, vol. 2, no. 2, 2011.

[12] F. Tradigo, F. Pisanò, C. Di Prisco, and A. Mussi, "Non-linear soil-structure interaction in disconnected piled raft foundations," Computers and Geotechnics, vol. 63, pp. 121-134, 2014.

[13] F. Tradigo, F. Pisanò, and C. di Prisco, "On the use of embedded pile elements for the numerical analysis of disconnected piled rafts," Computers and Geotechnics, vol. 72, pp. 89-99, 2016.

[14] S. Nakaia, H. Katoa, R. Ishidaa et al., "Load bearing mechanism of piled raft foundation during earthquake," in Proceedings of the of 3rd UJNR Workshop on Soil-Structure Interaction, pp. 29-30, March 2004.

[15] X. D. Cao, I. H. Wong, and M.-F. Chang, "Behavior of model rafts resting on pile-reinforced sand," Journal of Geotechnical and Geoenvironmental Engineering, vol. 130, no. 2, pp. 129-138, 2004.

[16] I. H. Wong, M. F. Chang, and X. D. Cao, "Raft foundations with disconnected settlement-reducing piles," in Design Applications of Raft Foundations, J. A. Hensley, Ed., chapter 17, Thomas Telford Ltd, 2000.
[17] V. Fioravante and D. Giretti, "Contact versus noncontact piled raft foundations," Canadian Geotechnical Journal, vol. 47, no. 11, pp. 1271-1287, 2010.

[18] V. Fioravante, "Load transfer from a raft to a pile with an interposed layer," Géotechnique, vol. 61, no. 2, pp. 121-132, 2011.

[19] M. Huang, F. Liang, and Z. Li, "Recent advances in the analysis of pile foundation in China," Doklady Akademii Nauk SSSR, vol. 302, no. 2, pp. 480-483, 2007.

[20] K. Horikoshi and M. F. Randolph, "On the definition of raft-soil stiffness ratio for rectangular rafts," Géotechnique, vol. 47, no. 5, pp. 1055-1061, 1997.

[21] J. Garnier and D. Konig, "Scale effects in piles and nails loading tests in sand," in Centrifuge '98, Tokyo, Japan, 23-25 September 1998, T. Kimura, O. Kusakabe, and J. Takemura, Eds., pp. 205210, Balkema, Rotterdam, The Netherlands, 1998.

[22] E. Christoph, T. Robert, and G. Daniel, Digital Image Correlation and Tracking with Matlab, 2006.

[23] T. K. Krein, Structural Mechanics of Granular Media, translated by C. Wanjia, China Railway Publishing House, Beijing, China, 1983.

[24] S. W. Abusharar, J. J. Zheng, B. G. Chen et al., "A simplified method for analysis of a piled embankment reinforced with geosynthetics," Geotextiles \& Geomembranes, vol. 27, no. 1, pp. 39-52, 2009.

[25] B. K. Low, S. K. Tang, and V. Choa, "Arching in piled embankments," Journal of Geotechnical Engineering, vol. 120, no. 11, pp. 1917-1938, 1994.

[26] British Standards Institution, "Code of practice for strengthened, reinforced soils and other fills," British Standard BS 8006:1995, 1995.

[27] V. A. Guido, J. D. Kneuppel, and M. A. Sweeny, "Plate loading tests on geogrid-reinforced earth slabs," in Proceedings of Geosynthetics '87, New Orleans, USA, pp. 216-225, IFAI, 1987.

[28] R. P. C. P. Chen, Y. M. C. M. Chen, J. H. Han, and Z. Z. $\mathrm{Xu}$, "A theoretical solution for pile-supported embankments on soft soils under one-dimensional compression," Canadian Geotechnical Journal, vol. 45, no. 5, pp. 611-623, 2008. 

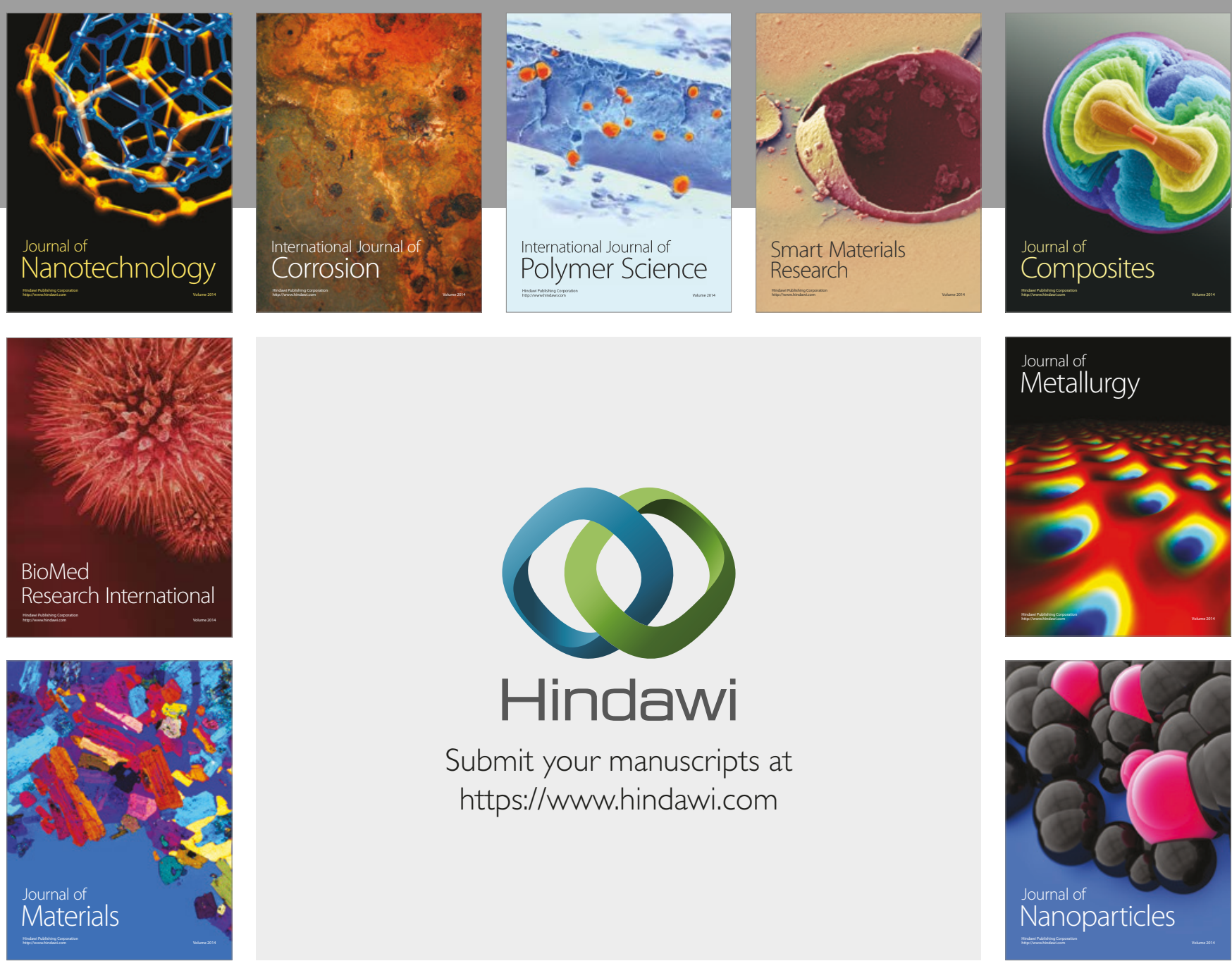

\section{Hindawi}

Submit your manuscripts at

https://www.hindawi.com
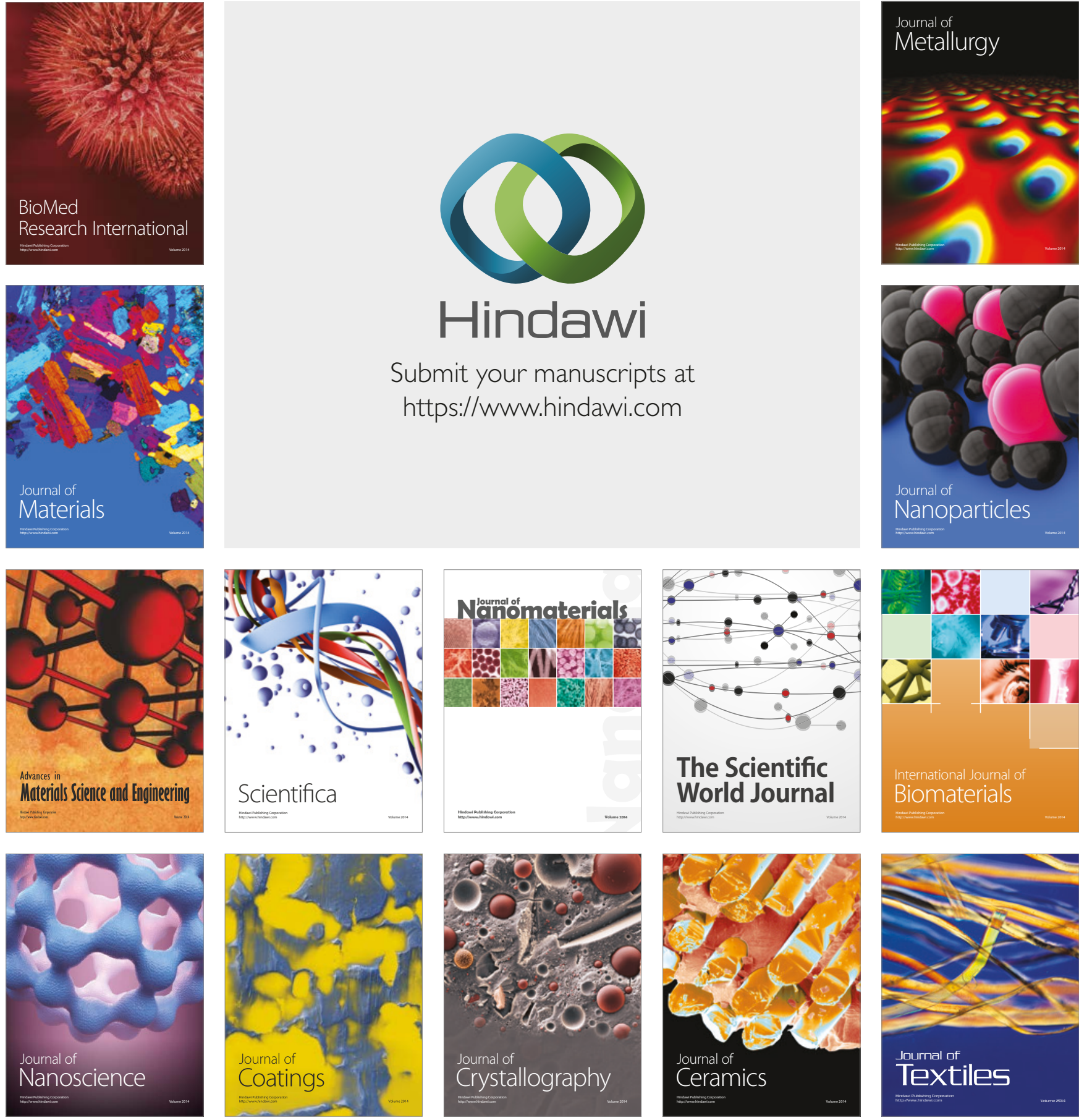

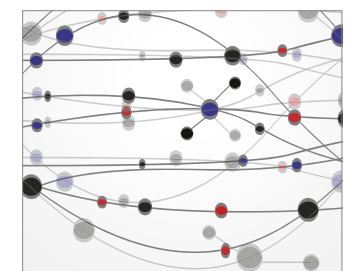

The Scientific World Journal
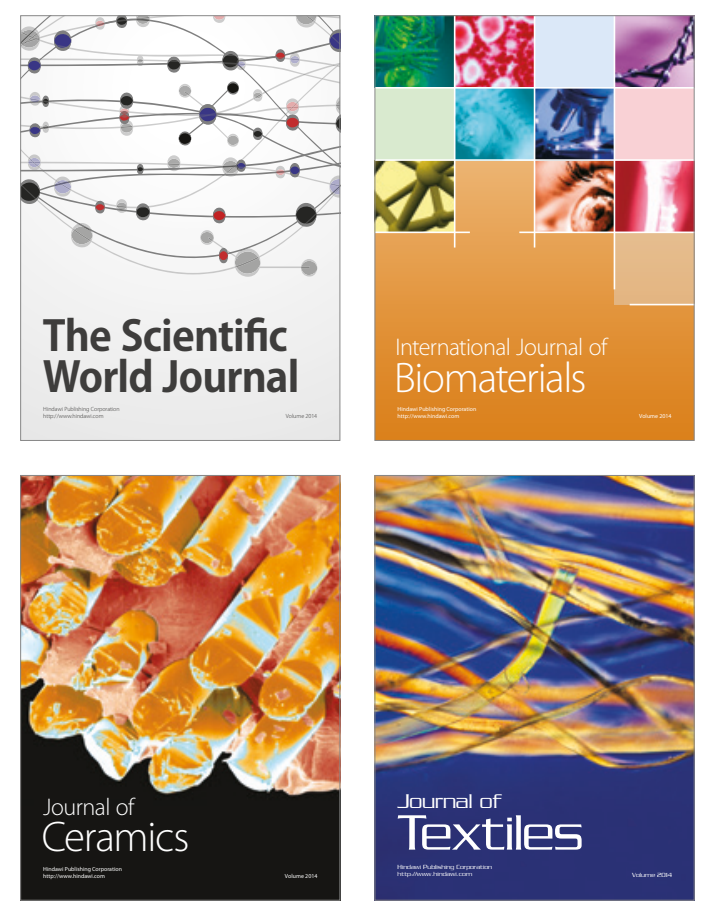